\title{
Emergency endovascular treatment using a Viabahn stent graft for upper and lower extremity arterial bleeding: a retrospective study
}

\section{Tatsuo Ueda ( $\sim$ s9015@nms.ac.jp)}

Nippon Medical School Hospital: Nihon Ika Daigaku Fuzoku Byoin https://orcid.org/0000-0002-07256880

\section{Satoru Murata}

Teikyo University Chiba Medical Center: Teikyo Daigaku Chiba Sogo Iryo Center

\section{Hiroyuki Tajima}

Saitama Medical University International Medical Center: Saitama Ika Daigaku Kokusai Iryo Center

\section{Hidemasa Saito}

Nippon Medical School Hospital: Nihon Ika Daigaku Fuzoku Byoin

\section{Daisuke Yasui}

Nippon Medical School Musashi Kosugi Hospital: Nihon Ika Daigaku Musashi Kosugi Byoin

\section{Fumie Sugihara}

Nippon Medical School Hospital: Nihon Ika Daigaku Fuzoku Byoin

\section{Shohei Mizushima}

Nippon Medical School Chiba Hokusoh Hospital: Nihon Ika Daigaku Chiba Hokuso Byoin

\section{Takahiko Mine}

Nippon Medical School Chiba Hokusoh Hospital: Nihon Ika Daigaku Chiba Hokuso Byoin

Hiroshi Kawamata

Yokohama Rosai Hospital: Yokohama Rosai Byoin

Hiromitsu Hayashi

Nippon Medical School Hospital: Nihon Ika Daigaku Fuzoku Byoin

\section{Shin-ichiro Kumita}

Nippon Medical School Hospital: Nihon Ika Daigaku Fuzoku Byoin

\section{Research Article}

Keywords: Viabahn, Stent graft, Upper extremity, Lower extremity, Arterial bleeding

Posted Date: October 1st, 2021

DOI: https://doi.org/10.21203/rs.3.rs-940898/v1 
License: (c) (i) This work is licensed under a Creative Commons Attribution 4.0 International License. Read Full License

Version of Record: A version of this preprint was published at CVIR Endovascular on December 1st, 2021. See the published version at https://doi.org/10.1186/s42155-021-00273-z. 


\section{Abstract}

\section{Background}

A Viabahn stent graft (SG) is a heparin-coated self-expandable SG for lower extremity arterial disease that exhibits high flexibility and accuracy in the delivery system. This study aimed to evaluate the shortterm efficacy and safety of emergency endovascular treatment (EVT) using a Viabahn SG for upper and lower extremity arterial bleeding (ULEAB).

\section{Methods}

Consecutive patients with ULEAB who underwent emergency EVT using the Viabahn SG between January 2017 and August 2021 were retrospectively reviewed. The indications for EVT, location of artery, technical success, clinical success, limb ischemia, periprocedural complications, bleeding-related mortality, 30-day mortality, diameter of the target artery, diameter of the SG, neck length, re-bleeding, endoleaks, and patency of the SGs at $1,3,6$, and 12 months were evaluated.

\section{Results}

EVT using Viabahn SG was performed in 22 patients (mean age: 72.0 years; 11 males) and 23 arteries (upper: 6, lower: 17). The indications for EVT were pseudoaneurysm $(n=13,59.1 \%)$, extravasation $(n=9$, $39.1 \%)$, and inadvertent arterial cannulation $(n=1,4.3 \%)$. The anatomical locations of the 23 ULEAB injuries were the brachiocephalic $(1[4.3 \%])$, subclavian (3 [13.0\%]), axillary (1 [4.3\%]), brachial (1 [4.3\%]), common iliac (4 [17.4\%]), external iliac (8 [34.8\%]), common femoral (2 [8.7\%]), superficial femoral (2 [8.7\%]), and popliteal (1 [4.3\%]) arteries. The technical and clinical success rates were $100 \%$. The rates of limb ischemia, periprocedural complications, and bleeding-related mortality were $0 \%$, whereas the 30 -day mortality rate was $22.7 \%$. The mean diameters of the arteries and SGs were 7.7 and $8.9 \mathrm{~mm}$, respectively. The mean neck length was $20.4 \mathrm{~mm}$. No endoleaks or re-bleeding occurred during the follow-up period (mean: 169 days). Two SG occlusions without limb ischemia occurred in the external iliac artery and brachial artery after 1 and 4 months, respectively. Subsequently, cumulative SG patency was confirmed after $1,3,6$, and 12 months in $91.7 \%, 91.7 \%, 81.5 \%$, and $81.5 \%$ of patients, respectively.

\section{Conclusions}

Emergency EVT using the Viabahn SG for ULEAB was effective and safe according to short-term outcomes. Appropriate size selection and neck length are important for successful treatment. SG patency was good after $1,3,6$, and 12 months.

\section{Background}

Conventionally, upper and lower extremity arterial bleeding (ULEAB) has been treated surgically; however, currently, a less invasive endovascular approach is favored [1-3]. Endovascular treatment (EVT) with a stent graft (SG) is ideal for ULEAB because it simultaneously allows for hemostasis and maintains the 
blood flow of peripheral limb arteries [3-7]. A Viabahn SG is a heparin-coated self-expandable SG for lower extremity arterial disease that exhibits high flexibility and accuracy in the delivery system. Compared with a balloon-expandable SG, this high flexibility is more suitable for endovascular repair of tortuous arteries or highly mobile areas, such as the axillary, iliac, common femoral, and popliteal arteries. Therefore, EVT with Viabahn SGs may be one of the best treatment options for ULEABs. Nevertheless, to date, reports regarding the outcomes of EVT with Viabahn SGs for ULEAB are limited [7-11]. This study aimed to evaluate emergency EVT using a Viabahn SG for ULEAB at various locations of arteries, focusing on technical aspects, efficacy, and safety.

\section{Methods}

\section{Patients}

This study included consecutive patients who underwent emergency EVT using the Viabahn SG for ULEAB between January 2017 and August 2021. The eligibility criteria were as follows: (1) evidence of ULEABs on computed tomography angiography (CTA), (2) diameter of the target vessel between 4 and 12 $\mathrm{mm}$, and (3) no contraindications to heparinization or contrast media. This study was approved by the institutional review board of our hospital, and informed consent was obtained from all patients before treatment.

\section{Endovascular procedure}

EVT was performed through a common femoral, brachial, axillary, or radial artery with a 4-Fr sheath (Supersheath; Medikit, Tokyo, Japan) under local anesthesia. A 4-Fr catheter (GLIDECATH; Terumo, Tokyo, Japan) was advanced to the distal side of the target artery with the aid of a 0.035 -inch guidewire (Radifocus Guide Wire M; Terumo, Tokyo, Japan). The guidewire was exchanged for a 0.035-inch stiff wire (Amplatz Super Stiff ${ }^{\text {Tw}}$; Boston Scientific, Natick, MA, USA) to exchange the sheath for a 6-14-Fr sheath (Medikit) or 6-Fr guiding sheath (Destination; Terumo, Tokyo, Japan). The sheath or guiding sheath was then advanced to the distal side of the target artery or as close to the target artery as possible. A 0.035 -inch stiff wire or 0.018 -inch stiff wire (V-18 ${ }^{\mathrm{TM}}$, Boston Scientific, Natick, MA) was used for SG delivery. The target artery was measured by either arteriography or pre-treatment CTA imaging. The diameter of the SG was approximately $110 \%$ of the diameter of the target artery. The length of the SG covered the entire target artery. The Viabahn (Gore, Flagstaff, AZ) SG (5-13 mm in diameter and 50 or $100 \mathrm{~mm}$ in length) was advanced until it covered the entire site of the target artery and was then deployed. In the case of a branch artery $>2 \mathrm{~mm}$ in diameter within $5 \mathrm{~mm}$ of the target artery, embolization of the branch artery was performed with coils (Tornade; Cook Medical, Bloomington, IN, Interlock; Boston Scientific, Natick, MA, USA) or an AMPLATZER ${ }^{\text {TM }}$ Vascular Plug 2 (AVP 2; St. Jude Medical, St. Paul, MN) to avoid a type 2 endoleak (EL). An angiogram was immediately performed after the deployment without post-dilatation of the SG. If the angiogram showed type 1 or type $3 \mathrm{EL}$, an additional percutaneous transluminal angioplasty with the same SG diameter and/or an additional SG placement that partially overlapped the first SG was performed to treat the EL. After the procedure, if there were no 
contraindications, anticoagulation therapy based on dual antiplatelet therapy (aspirin $100 \mathrm{mg} / \mathrm{day}$ and clopidogrel $75 \mathrm{mg} /$ day) was prescribed for at least 6 months to prevent SG thrombosis. Follow-up CTA was performed at 1, 3, 6, and 12 months after treatment.

\section{Assessment of endovascular treatment efficacy}

The following data were collected: enrolled patient number, age, sex, cause, indication, location, approach site, diameter of the target artery, diameter of the SG, oversizing of the SG, length of the SG, neck length, branch artery embolization, procedure time, anticoagulation therapy, and CTA follow-up duration. Neck length was defined as the minimum distance between the edge of the SG and the injured or bleeding point. The technical success, clinical success, limb ischemia, periprocedural complications, bleedingrelated mortality, 30-day mortality, re-bleeding, ELs, and SG patency were assessed at 1, 3, 6, and 12 months. Technical success was defined as the disappearance of the pseudoaneurysm and extravasation with preserved blood flow in the limb artery on the angiogram. Clinical success was defined as complete hemostasis within 30 days of the procedure. Limb ischemia was defined as ischemic sequelae of the limb of the target artery. Complications were defined as major complications that required therapy, according to the Society of Interventional Radiology classification [12]. Re-bleeding, ELs, and SG patency were evaluated using CTA images.

\section{Statistical analyses}

Continuous variables are presented as mean \pm standard deviation, whereas categorical data are presented as percentages. Kaplan-Meier analyses were performed for SG patency using the Statistical Package for the Social Sciences version 21 (IBM Corp., Armonk, NY, USA).

\section{Results}

\section{Patient characteristics}

A summary of the results is provided in Table 1. The study included 22 patients (mean age: $72.0 \pm 12.3$ years; 11 males) with 23 ULEAB injuries, as one patient had two ULEAB injuries. ULEAB injuries were noted in the arteries, including the brachiocephalic $(n=1)$, subclavian $(n=3)$ (Fig. 1), axillary $(n=1)$, brachial $(n=1)$, common iliac $(n=4)$, external iliac $(n=8)$ (Fig. 2), common femoral $(n=2)$, superficial femoral $(n=2)$, and popliteal $(n=1)$ arteries. The causes of ULEAB were post-endovascular therapy $(n=$ $9)$, postoperative complications $(n=3)$, idiopathic causes $(n=3)$, infection $(n=2)$, trauma $(n=2)$, carcinoma $(n=2)$, and post-radiation therapy $(n=1)$. The indications for EVT included pseudoaneurysms $(n=13)$, extravasation (9), and inadvertent arterial cannulation (1). 


\section{Factor}

Patients

Cases

Age (years, mean $\pm S D$ )

Sex (male/female)

Indication

(pseudoaneurysm/extravasation/inadvertent arterial cannulation)

Location of the artery

(BCA/SCA/AXA/BA/CIA/EIA/CFA/SFA/POP)

Approach site (femoral/axillary/brachial/radial)

Artery diameter $(\mathrm{mm}$, mean $\pm \mathrm{SD})$

Stent graft diameter $(\mathrm{mm}$, mean $\pm \mathrm{SD})$

Stent graft oversizing $(\%$, mean \pm SD)

Stent graft length $(5 / 10 \mathrm{~cm})$

Neck length $(\mathrm{mm}$, mean $\pm \mathrm{SD})$

Branch artery embolization

Procedure time (min, mean \pm SD)

Technical success (\%)

Clinical success (\%)

Limb ischemia (\%)

Periprocedural complications (\%)

Bleeding-related mortality (\%)

30-day mortality (\%)

Anticoagulation therapy (\%)

CTA follow-up duration (days, mean \pm SD)
22

23

$72.0 \pm 12.3$ (range: $36-90$ )

$11 / 11$

$13 / 9 / 1$

$1 / 3 / 1 / 1 / 4 / 8 / 2 / 2 / 1$

$20 / 1 / 1 / 1$

$7.7 \pm 2.2$ (range: $5-12$ )

$8.9 \pm 2.3$ (range: $6-13$ )

$16.1 \pm 7.8$ (range: $0-33$ )

$20 / 8$

$20.4 \pm 11.3$ (range: $3-50$ )

3

$35.5 \pm 21.2$ (range: $8-86$ )

100

100

0

0

0

22.7

77.3

$168.8 \pm 176.5$ (range: $3-655$ )

$A X A$, axillary artery; $B A$, brachial artery; $B C A$, brachiocephalic artery; $C F A$, common femoral artery; $C I A$, common iliac artery; CTA, computed tomography angiography; EIA, external iliac artery; POP, popliteal artery; SCA, subclavian artery; SFA, superficial femoral artery; SD, standard deviation. 


\section{Factor}

$\begin{array}{lll}\text { Re-bleeding (\%) } & 0 \\ \text { Endoleaks (\%) } & & 0 \\ \text { Stent graft patency (\%) } & 1 \text { month } & 91.7 \\ & 3 \text { months } & 91.7 \\ & 6 \text { months } & 81.5 \\ & 12 \text { months } & 81.5\end{array}$

$A X A$, axillary artery; $B A$, brachial artery; $B C A$, brachiocephalic artery; $C F A$, common femoral artery; $C I A$, common iliac artery; CTA, computed tomography angiography; EIA, external iliac artery; POP, popliteal artery; SCA, subclavian artery; SFA, superficial femoral artery; SD, standard deviation.

\section{Procedure results}

EVT was performed through the common femoral artery in 20 patients, brachial artery in one patient, axillary artery in one patient, and radial artery in one patient. The brachial artery approach was used in cases where it was impossible to approach the common femoral artery, the axillary artery approach was used in cases where it was impossible to approach the common femoral artery and a 14-Fr sheath was required, and the radial artery approach was used in the treatment of brachial artery pseudoaneurysm. The mean diameters of the arteries and SGs were $7.7 \pm 2.2 \mathrm{~mm}$ (range: 5-12 mm) and $8.9 \pm 2.3 \mathrm{~mm}$ (range: 6-13 mm), respectively. The 5-mm SG was selected for 20 patients, and the 10-mm SG was selected for eight patients. The mean neck length was $20.4 \pm 11.3 \mathrm{~mm}$ (range: $3-50 \mathrm{~mm}$ ) in all patients. Branch artery embolization was performed in three patients (one vertebral artery case and two internal iliac artery cases) (Fig. 1). The mean procedure time was $35.5 \pm 21.2$ (range: 8-86) min.

\section{Initial and midterm results}

Technical and clinical success was achieved in all patients. Ischemia of the limbs and periprocedural complications were both at $0 \%$. Five patients died 3, 6, 13, 24, and 29 days after SG treatment because of acute myocardial infarction in two, carcinoma in two, and bowel ischemia in one patient, respectively. Therefore, the 30-day mortality rate was $22.7 \%$ (5/22). However, there were no bleeding-related deaths. Anticoagulation therapy was prescribed to 17 of the 22 patients (77.3\%). CTA postoperative follow-ups were performed on 15 of the 22 patients (68.2\%), and the mean CTA follow-up period was $168.8 \pm 176.5$ (range: 3 - 655) days. No re-bleeding or EL was observed during the CTA follow-up period. Two SG occlusions without limb ischemia occurred in the external iliac artery and brachial artery after 1 and 4 months, respectively. Subsequently, cumulative SG patency was confirmed after 1, 3, 6, and 12 months in $91.7 \%, 91.7 \%, 81.5 \%$, and $81.5 \%$ of patients, respectively (Fig. 3). The patient with SG occlusion in the brachial artery only received aspirin when the SG occlusion occurred, and the target artery and SG diameters were 6 and $8 \mathrm{~mm}$, respectively. The other occluded patient in the external iliac artery had iliac 
occlusion disease prior to the SG treatment. We did not treat the SG occlusions because both patients were asymptomatic.

\section{Discussion}

The technical and clinical success rates were consistent with those in previous studies, at $97-100 \%$ [811]. Appropriate diameter size selection is important to avoid re-bleeding and type 1 ELs (T1ELs). Since the most important goal in treating ULEAB is hemostasis, avoiding an undersized diameter is crucial. Neck length is also a critical factor in avoiding re-bleeding and T1EL. It should be secured at a minimum of $20 \mathrm{~mm}$, according to the manufacturer's instructions. We used a mean neck length of 20.4 (range: 350) $\mathrm{mm}$ without observing any T1EL. These results suggest that it is possible to treat ULEAB without T1EL if the diameter size selection and neck length are appropriate. Our SG patency was consistent with those reported in previous studies at $68-100 \%$ [8-11]. It is difficult to identify the cause of occlusion; however, anticoagulation therapy, oversized SG, location, infection, and smaller vessel diameters might be contributing factors. Saxon et al. reported that with Viabahn SG, patency in femoropopliteal artery disease was significantly lower with devices oversized by $>20 \%$ than with devices oversized by $<20 \%$ [13]. Furthermore, Ueda et al. showed that patients with $>20 \%$ oversized SG had higher risk of SG occlusion [4]. However, we used a device oversized by $>20 \%$ (8-mm SG for a 6-mm artery diameter) in an SG occlusion case and did not need to treat the occlusions, as there was no evidence of limb ischemia due to the development of collateral circulation. However, limb arteries are potentially at risk of ischemia; therefore, SG occlusion should be prevented.

In conclusion, emergency EVT using a Viabahn SG for ULEAB was effective and safe for short-term outcomes, with low rates of limb ischemia, periprocedural complications, and bleeding-related mortality. Appropriate size selection and neck length are important for successful treatment. SG patency was good after 1, 3, 6, and 12 months. Long-term follow-up and a larger sample size are suggested for further treatment evaluation.

\section{Abbreviations}

CTA, computed tomography angiography; EL, endoleak; EVT, endovascular treatment; ULEAB, upper and lower extremity arterial bleeding; SG, stent graft

\section{Declarations}

\section{Ethics approval and consent to participate}

This study was approved by the institutional review board of our university hospital.

\section{Consent for publication}

Consent for publication was obtained for every individual person's data included in the study. 


\section{Availability of data and materials}

Data sharing is not applicable to this article as no datasets were generated or analyzed during the current study.

\section{Competing interests}

The authors declare that they have no competing interests.

\section{Funding}

Not applicable.

\section{Authors' contributions}

T.U. performed the literature review and drafted the manuscript. S.M. and H.T. were the consultant interventional radiologists who participated in the study design and edited the manuscript. H.S., D.Y., F.S., S.M., T.M., and H.K. were the interventional radiologists who performed the intervention in the cases. H.H. and S.K. were the consultants of the diagnostic radiologist who edited the manuscript. All authors read and approved the final manuscript.

\section{Acknowledgments}

Not applicable.

\section{References}

1. Van Waes O, Navsaria P, Verschuren R, Vroon L, Van Lieshout EM, Halm JA et al (2013) Management of penetrating injuries of the upper extremities. Ulus Travma Acil Cerrahi Derg 19:405-410. https://doi.org/10.5505/tjtes.2013.08684

2. Fox N, Rajani RR, Bokhari F, Chiu WC, Kerwin A, Seamon MJ et al (2012) Evaluation and management of penetrating lower extremity arterial trauma: an Eastern Association for the Surgery of Trauma practice management guideline. J Trauma Acute Care Surg 73:315-320. https://doi.org/10.1097/TA.0b013e31827018e4

3. Katsanos K, Sabharwal T, Carrell T, Dourado R, Adam A (2009) Peripheral endografts for the treatment of traumatic arterial injuries. Emerg Radiol 16:175-184. https://doi.org/10.1007/s10140008-0771-9

4. Ueda T, Murata S, Tajima H, Saito H, Yasui D, Sugihara F et al (2021) Endovascular treatment with Viabahn stent-grafts for arterial injury and bleeding at the visceral arteries: initial and midterm results. Jpn J Radiol. Online ahead of print. https://doi.org/10.1007/s11604-021-01192-8

5. Venturini M, Marra P, Colombo M, Alparone M, Agostini G, Bertoglio L et al (2017) Endovascular treatment of visceral artery aneurysms and pseudoaneurysms in 100 patients: covered stenting vs 
transcatheter embolization. J Endovasc Ther 24:709-717.

https://doi.org/10.1177/1526602817717715

6. Ueda T, Tajima H, Murata S, Takagi R, Yokota H, Kumita SI (2017) Chopstick injury: successful stentgraft therapy for traumatic left subclavian artery aneurysm. J Nippon Med Sch 84:41-44. https://doi.org/10.1272/jnms.84.41

7. Ormiston W, Merrilees S, Hill A, Brew S, McGuinness B, Holden A (2020) Management of inadvertent proximal vertebral artery cannulation by a combined endovascular/surgical approach. Cardiovasc Intervent Radiol 43:1946-1948. https://doi.org/10.1007/s00270-020-02619-x

8. DuBose JJ, Rajani R, Gilani R, Arthurs ZA, Morrison JJ, Clouse WD et al, Endovascular Skills for Trauma and Resuscitative Surgery Working Group (2012) Endovascular management of axillosubclavian arterial injury: a review of published experience. Injury 43:1785-1792. https://doi.org/10.1016/j.injury.2012.08.028

9. Kufner S, Cassese S, Groha P, Byrne RA, Schunkert H, Kastrati A et al (2015) Covered stents for endovascular repair of iatrogenic injuries of iliac and femoral arteries. Cardiovasc Revasc Med 16:156-162. https://doi.org/10.1016/j.carrev.2015.02.007

10. De Backer O, Arnous S, Sandholt B, Brooks M, Biasco L, Franzen O et al (2015) Safety and efficacy of using the Viabahn endoprosthesis for percutaneous treatment of vascular access complications after transfemoral aortic valve implantation. Am J Cardiol 115:1123-1129.

https://doi.org/10.1016/j.amjcard.2015.01.547

11. Desai SS, DuBose JJ, Parham CS, Charlton-Ouw KM, Valdes J, Estrera AL et al (2014) Outcomes after endovascular repair of arterial trauma. J Vasc Surg 60:1309-1314.

https://doi.org/10.1016/j.jvs.2014.05.016

12. Khalilzadeh O, Baerlocher MO, Shyn PB, Connolly BL, Devane AM, Morris CS et al (2017) Proposal of a new adverse event classification by the society of interventional radiology standards of practice committee. J Vasc Interv Radiol 28:1432-1437. https://doi.org/10.1016/j.jvir.2017.06.019

13. Saxon RR, Chervu A, Jones PA, Bajwa TK, Gable DR, Soukas PA et al (2013) Heparin-bonded, expanded polytetrafluoroethylene-lined stent graft in the treatment of femoropopliteal artery disease: 1-year results of the VIPER (Viabahn Endoprosthesis with Heparin Bioactive Surface in the Treatment of Superficial Femoral Artery Obstructive Disease) trial. J Vasc Interv Radiol 24:165-173. https://doi.org/10.1016/j.jvir.2012.10.004

\section{Figures}




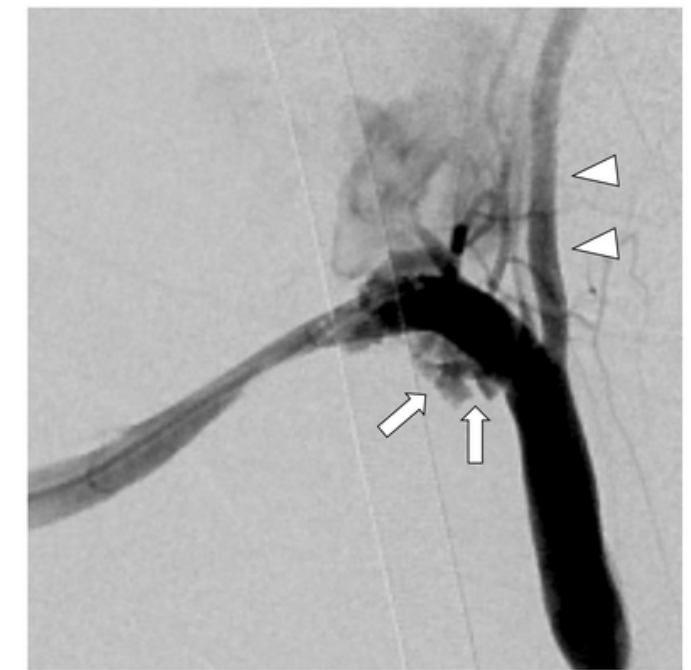

B

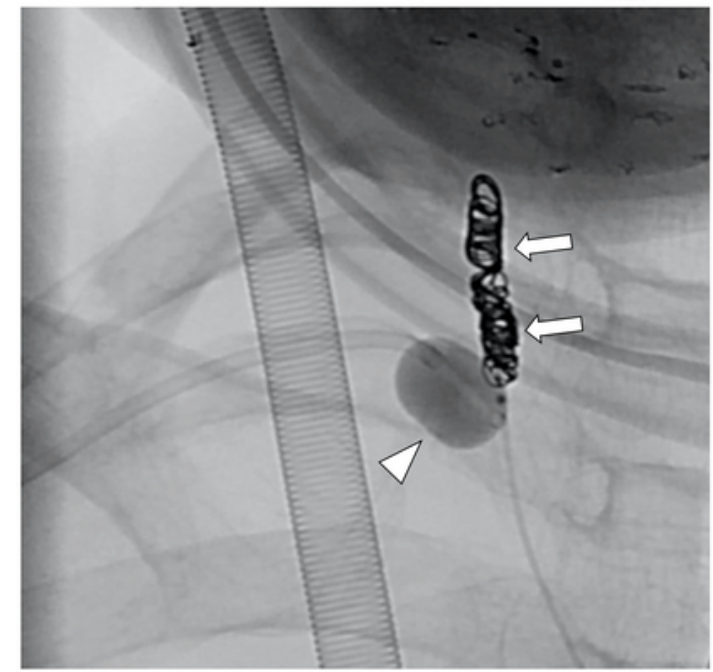

C

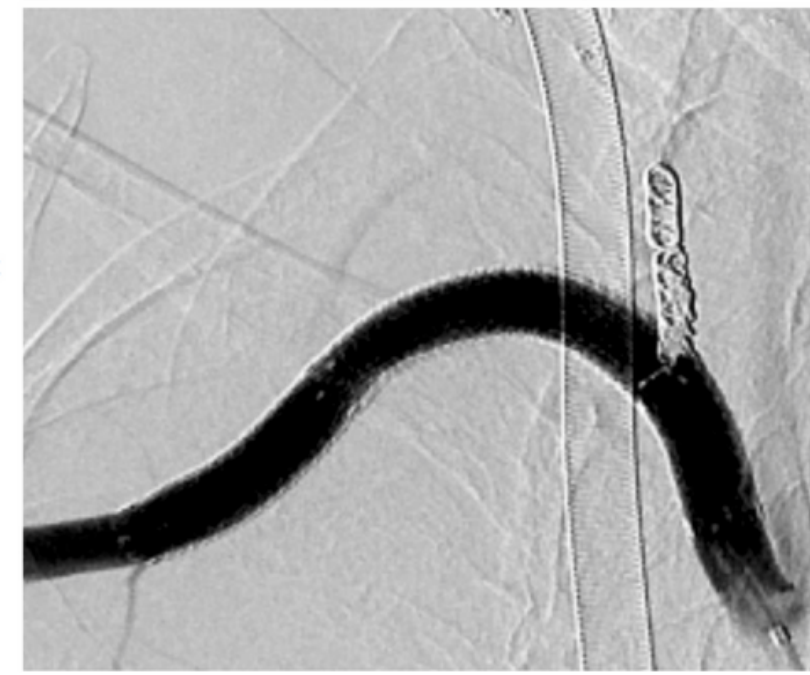

Figure 1

A 64-year-old woman with right subclavian artery injury by an inadvertent puncture a Pre-treatment angiogram shows extravasation from the proximal site of the right subclavian artery (arrows). The right vertebral artery branches close to the extravasation (arrowheads). b The right vertebral artery was embolized by coils (arrows) to avoid type 2 endoleaks under balloon occlusion (arrowhead) of the right 
subclavian artery. c Angiogram after endovascular therapy with Viabahn stent grafts $(8 \mathrm{~mm} \times 5 \mathrm{~cm}$ and 8 $\mathrm{mm} \times 10 \mathrm{~cm}$ ) shows the disappearance of the extravasation without endoleak.

A

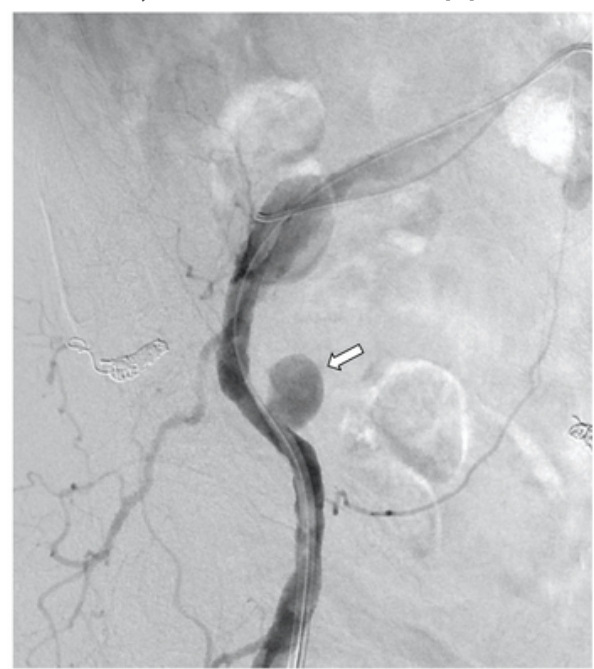

B

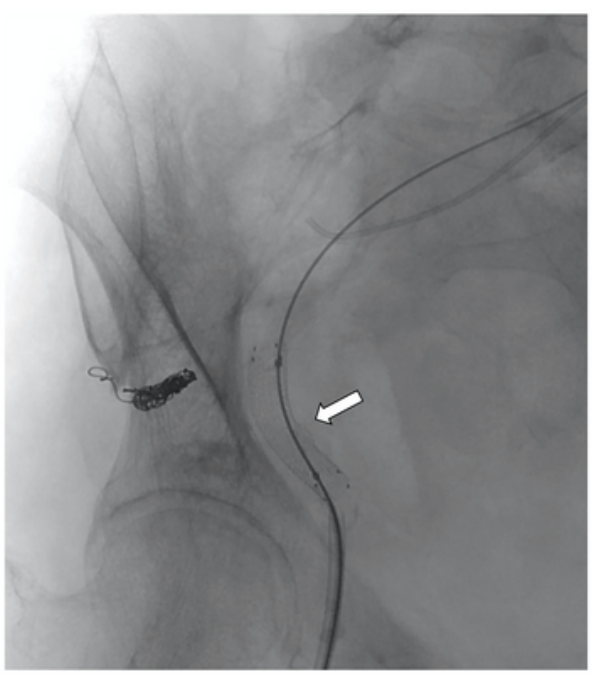

C

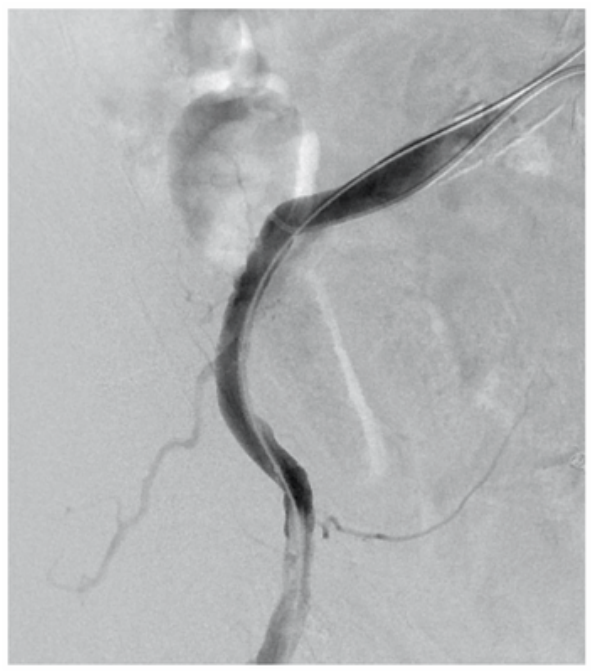

Figure 2

A 76-year-old woman with right external iliac artery pseudoaneurysm by uterine carcinoma a Pretreatment angiogram shows a pseudoaneurysm from the distal site of the right external iliac artery (arrow). b The Viabahn stent graft $(9 \mathrm{~mm} \times 5 \mathrm{~cm}$ ) (arrowhead) is placed at the external iliac artery. c 
Angiogram after endovascular therapy with a Viabahn stent graft shows disappearance of the pseudoaneurysm without endoleak.

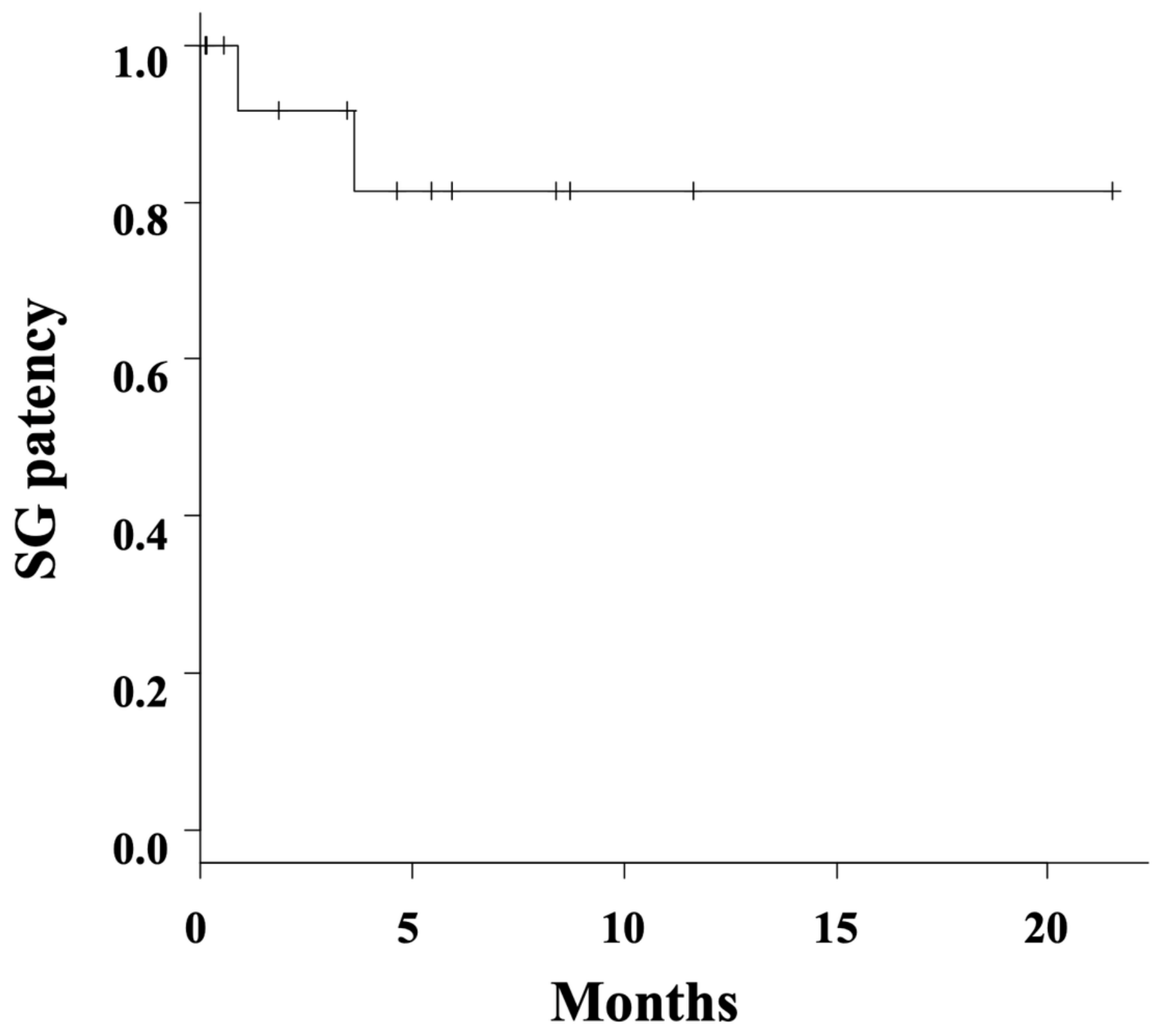

Figure 3

Stent graft patency A Kaplan-Meier curve reveals stent graft patency over time for the Viabahn stent grafts. The transverse axis shows the time (months) after the procedure. SG, stent graft 